\title{
Low birth weight in Mexico: New evidence from a multi-site postpartum hospital survey
}

\author{
Reanne Frank, PhD, (1) Blanca Pelcastre, PhD, (2) V N elly Salgado de Snyder, PhD, (2) W Parker Frisbie, PhD, (3) \\ Joseph E Potter, PhD, ${ }^{(3)}$ Mario N Bronfman-Pertzovsky, PhD. ${ }^{(2)}$
}

\begin{abstract}
Frank R, Pelcastre B, Salgado de Snyder VN, Frisbie WP, Potter JE, Bronfman-Pertzovsky MN. Low birth weight in Mexico: New evidence from a multi-site postpartum hospital survey. Salud Publica Mex 2004;46:23-31. The English version of this paper is available too at: http://www.insp.mx/salud/index.html
\end{abstract}

\begin{abstract}
A bstract
Objective. To identify factors related to cases of low birth weight among a sample of Mexican women. Material and Methods. The present analysis utilizes data from a post partum survey of 565 women implemented in eight different so cial security hospitals in western M exico during 2001. Women giving birth to low weight infants ( $2.5 \mathrm{kgs})$ were oversampled and make up half of the sample. Results. A series of logistic regression equations are presented that estimate the risk of low birth weight. Study findings indicate that, although behavioral factors appear to be highly significant in predicting the odds of low birth weight, socioeconomic and sociodemographic factors were found to be important in determining utilization of prenatal care. Conclusions. The key role of behavioral characteristics in determining low birth weight risk and the role of socioeconomic and sociodemographic factors in determining prenatal care usage highlights the need to improve prenatal care utilization by disadvantaged populations. The English version of this paper is available too at: http://www.insp.mx/salud/ index.htm
\end{abstract}

Key words: low birth weight; infant mortality; infant health; perinatal care; Mexico
Frank R, Pelcastre B, Salgado de Snyder VN, FrisbieW P, Potter JE, Bronfiman-Pertzovsky MN. Bajo peso al nacer en México: nueva evidencia a partir de una encuesta postparto multi-hospitalaria. Salud Publica Mex 2004;46:23-31.

El texto completo en inglés de este artículo también está disponible en: http://www.insp.mx/salud/index.html

\section{Resumen}

Objetivo. Identificar los factores relacionados con el bajo peso al nacer en mujeres mexicanas. Material y métodos. Se analizan datos de una encuesta recientemente aplicada en 2001 a 565 mujeres en condición de posparto, en ocho hospitales de la Secretaría de Salud, en el O ccidente de la República M exicana, que permite una evaluación detallada de los factores que contribuyen al riesgo de bajo peso. La mitad de las mujeres había dado a luz a recién nacidos de bajo peso (menos de $2.5 \mathrm{kgs}$ ) y el resto de peso normal. Este trabajo presenta los resultados de una serie de regresiones logisticas que estiman el riesgo de bajo peso al nacer. Resultados. Los resultados indican que mientras los factores de comportamiento están aso ciados significativamente al bajo peso al nacer, los factores sociodemográficos y socioeconómicos están más relacionados con la utilización de servicios de atención prenatal. Conclusiones. El papel clave de las características de comportamiento en la determinación del riesgo del bajo peso y el papel de los factores sociodemo gráficos y socio económicos en la determinación de atención prenatal, enfatizan la necesidad de incrementar la utilización de servicios de atención prenatal por parte de los sectores más desfavorecidos de la población. El texto completo en inglés de este artículo también está disponible en: http://www.insp.mx/salud/index.html

Palabras clave: bajo peso al nacer; mortalidad infantil; salud perinatal; cuidado prenatal; México

This work was supported by grants from the Andrew W Mellon Foundation (Latin American Fellowship Program in Sociology and Center Grant for the Study of U rbanization and Internal Migration in D eveloping C ountries, Population Research C enter, University of Texas at Austin).

(1) The 0 hio State University, Estados Unidos de América.

(2) Instituto Nacional de Salud Pública. Cuernavaca, Morelos, México.

(3) University of Texas at Austin, Estados Unidos de América.

Received on: February 12,2003 • Accepted on: August 1,2003

Address reprint requests to: Reanne Frank.The 0 hio State University 300 Bricker Hall. Columbus, 0 H 43210. USA. E- mail: reanne10@yahoo.com 
0 ver the last century, great advances have been made in Mexican perinatal health. In 1930, 178 of every 1000 live births resulted in an infant death. By 2002 , this number had fallen to 21, a decrease of over 80 percent. ${ }^{1,2}$ The uninterrupted continuous decline in Mexico's infant mortality rate has largely been driven by improvements in socioeconomic development and primary health care that have affected the causes of death most frequent in the postnatal period (deaths occurring after 27 days and before 1 year of age). ${ }^{3}$ Beginning in 1980, when reliable data first became available, infectious disease and respiratory infections accounted for over one half of all infant deaths; by 2000, they represented less than one-fifth of all deaths. ${ }^{4}$ In turn, perinatal complications and congenital abnormalities now account for over two thirds of all infant deaths. Due to these shifts in Mexico's distribution of death causes, infant mortality has become increasingly concentrated in the neonatal period (before 27 days of age) among premature and low birth weight infants. As a result, low birth weight has become an increasingly important factor in determining infant mortality risk (for an alternative perspective see Wilcox 2001). ${ }^{5}$

The purpose of the present analysis was to identify factors related to low birth weight in Mexico, using a recent hospital-based postpartum survey. By learning more about factors that contribute to low birth weight, this research informs practices that aim to decrease infant mortality, as well as the subsequent poorer child health and development outcomes that continue to plague children of low birth weight later in life. ${ }^{6}$

The analyses also focus on the receipt of prenatal care, given the positive association between receipt of care and birth weight. ${ }^{7}$ Prenatal care includes educating women about pregnancy, labor and delivery, linking women to other valuable social services, encouraging healthy lifestyle choices, and identifying and treating maternal morbidities., ${ }^{8,9}$

Much of the literature in the area of infant health considers birth weight as an endpoint in a series of links between socioeconomic background characteristics and more proximate determinants. ${ }^{10,11}$ Most causally distant from low birth weight are social factors, including education level, standard of living, and living conditions. Level of education and household infrastructure are two socioeconomic variables most commonly operationalized in infant health research in Mexico and both have been found to be inversely related to the odds of low birth weight. ${ }^{12,13}$ Maternal work experience has also been linked to low birth weight in
Mexico, although the direction of the relationship has been subject to debate. Several studies suggest that type of work is a critical variable for determining the relationship. Women working under mentally stressful working conditions, in laborious jobs, or working for more than 50 hours a week, all experienced a significantly increased risk of low-weight birth. ${ }^{14,15}$ Socioeconomic position interacts with sociodemographic factors to influence an individual's social position. These include: young age, first births, and unwed marital status, all of which have been linked to the incidence of low-weight births. 13,16

While sociodemographic and socioeconomic factors are important driving forces in determining health risks, they are not usually considered to influence infant health outcomes directly. Rather, they contribute to the incidence of low birth weight by patterning distributions along other more proximate factors, such as behavioral or maternal lifestyle characteristics. ${ }^{17}$ These behaviors are influenced by socioeconomic background factors to the degree that social position affects the ability to control everyday life circumstances and influences major lifestyle choices. Maternal lifestyle behaviors that have been shown to influence birth weight include: drug and alcohol use, cigarette smoking, diet and nutrition, exercise, stress levels, vitamin use, and prenatal care. ${ }^{18}$ Maternal lifestyle choices impinge on infant health largely through biological pathways, and for this reason maternal health indicators are the most proximately related to infant birth weight.

\section{Material and Methods}

The data used in this analysis come from a primary data collection effort conducted in 2001. A hospitalbased postpartum survey (HPS) was administered to a sample of women who had given birth in one of eight different hospitals located in the Mexican states of Jalisco and Michoacán. The focus of the survey was on factors related to low birth weight.

The hospital sites were restricted to those that fell under the umbrella of the Ministry of Health (Secretaría de Salud de México-SSA), which provides health services to the uninsured Mexican population, as one of the objectives of this survey was to examine the relationship between low birth weight and disadvantaged social status. An over-sample of low-weight births was conducted in order to ensure a sufficient sample size with which to conduct reliable statistical analyses. Hospital records were used to ascertain the volume of births occurring in each possible hospital 
site and the prevalence of low birth weights among the births. The final eight hospitals chosen represented a mix of technological sophistication and size.

The sample respondents were 565 women selected based on the birth weight of their infant. In each hospital, trained female interviewers (nurses, social workers) were instructed to invite every available woman who had given birth to a low-weight infant during the data collection period to take part in the survey. Among women who had given birth to a normal weight infant, interviewers randomly selected the participants. Women were explained the purpose of the study and consent was obtained prior to the interview. The final sample size resulted in 565 infants, 257 low birth weight infants ( $<2500$ grams) and 308 normal weight infants ( $\geq 2500$ grams). In all the analyses, weights were utilized that adjust for the sampling design.

In the first set of analyses, low birth weight was the outcome of interest and was treated as a dichotomous variable so that infants weighing less than 2500 grams at birth were defined as low birth weight. The data on infant birth weight were highly reliable as they were collected directly from the hospital files. There were no missing cases for the outcome variable.

The sociodemographic factors included maternal age, marital status, and parity status. Maternal age was coded using the three categories that divide women into young ( $<20$ years), middle age (20-34 years), and older mothers (35+), in order to capture the often curvilinear shape of maternal age and infant health distribution. Parity was operationalized using the Kleinman and Kessel Index ${ }_{1}^{19}$ in which birth order and maternal age are combined to result in three categories: a) First birth; b) Low parity (second-order births to women 18 and older, third order births to women 25 and older), and c) High parity (second- or higherorder births to women under 18, third- or higher-order births to women under 25, and fourth- and higher-order births to women 25 and older. Marital status was measured at the beginning of the pregnancy and differentiates between formal and informal unions.

The socioeconomic indicators chosen for this analysis included those that have in the past proven important in contributing to health outcomes in Mexico. ${ }^{20}$ Maternal education level was coded to distinguish between women who had received no formal education, women who have had less than a primary school education ( $<6$ years) and women who had completed primary school or more. Also, women who reported working at any time during the pregnancy were differentiated from women who did not work at all during their pregnancy. With regard to socioeconomic context variables, a dichotomous indicator measuring locality size was included to differentiate large metropolitan areas (100 000+ inhabitants) from areas with less than 100000 inhabitants. A measure of household infrastructure as a proxy for general socioeconomic condition was also included. Women were asked a series of questions concerning the household infrastructure of the house in which they spent the majority of their pregnancy. Lack of indoor sanitation or water facilities, lack of electricity, and the presence of dirt floors, were all considered indicators of poor household infrastructure. These indicators were then added to count the number of household infrastructure problems. In the descriptive statistics, each of the indicators is presented separately, and in the regression models the number of household infrastructure problems is included as a continuous variable.

With regard to behavioral practices, three measures were included as general indicators of a healthy maternal lifestyle and have been identified in past literature as linked to the prevalence of low birth weight. ${ }^{18}$ They include maternal smoking, prenatal care utilization, and maternal weight gain during pregnancy. In this analysis, women who smoked at any point during their pregnancy were coded as smokers. With regard to weight gain, each respondent was asked how much weight she gained during her pregnancy, if she did not know the answer, she was assigned to a missing category. Women were defined as gaining an insufficient amount of weight if they gained less than 7 kilograms during the pregnancy. ${ }^{21} \mathrm{~A}$ third measure of maternal lifestyle involved having obtained prenatal care. In the models predicting birth weight, prenatal care was captured with a three-level variable that differentiates between the time of the first prenatal care visit, as timing is a key component determining the adequacy of prenatal care. ${ }^{22}$ Based on whether the respondent attended her first prenatal care visit within the first three months of pregnancy, she was coded as having received prenatal care either early or late in pregnancy. The definition of prenatal care was restricted to health care that is provided by a physician or a nurse.

Maternal health is a key intervening variable for risk of low birth weight. The analysis included several medical indicators that captured the general health of respondents during pregnancy. Respondents who were hospitalized at any time during the pregnancy were differentiated from those who were not. Furthermore, women who reported having any of the following problems during pregnancy were coded as having experienced health problems: vaginal bleeding, urinary tract infection, bladder infection, other infection, dia- 
betes, premature labor pains, high fever, weakness/ fatigue, hypertension/high blood pressure, nervios, other health problems. These conditions were based on self-report and were not obtained from medical records. Although subjective health reporting has been found to be a reliable indicator of overall health status, it remains inferior to medical reports with regard to the reporting of specific conditions. Thus, the distributions of health problems should be treated with caution. ${ }^{23}$

Following a description of the distribution of birth weight and risk factors, two sets of models were constructed. The first uses logistic regression to estimate the effect of three different sets of covariates on the likelihood of giving birth to a low weight infant. Nested models were built hierarchically to evaluate the exploratory power of the different sets of factors. The first model included sociodemographic and socioeconomic background factors, the most causally distant from low birth weight. The second model added maternal lifestyle factors, through which the background factors are understood to influence infant health. The third model included maternal health indicators, which are the most causally proximate to low birth weight.

The second set of models used logistic regression to estimate the effects of two sets of covariates on the likelihood of receiving prenatal care. By modeling receipt of prenatal care, we hoped to better understand the factors influencing care utilization. When prenatal care was included as the dependent variable, it was measured dichotomously as whether or not the respondent received some type of prenatal care by a physician or nurse during the pregnancy, regardless of the timing of the initial visit. The first model added the sociodemographic and socioeconomic factors in order to evaluate if the odds of receiving prenatal care differed by sub-group. A second model added controls for maternal health problems, which may provide a stimulus for women to actively seek out prenatal care.

The survey was based on a sample design that involved stratification by month, hospital, and birth weight. Weights were created based on the inverse of the selection probability. The regression models were run using Stata 7 software, which adjusts coefficients and standard errors to take the sampling design into account. ${ }^{24}$

\section{Results}

Table I presents the percentage distribution of the variables used in the analysis. Around 7\% of the births in the sample were low birth weight, a figure that closely matches those obtained in Mexican national samples.
Table I

Percentage distribution of selected variable. Hospital based post partum survey, Mexico, 2001

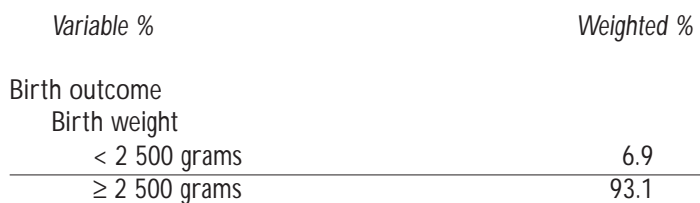

Source: Hospital-based postpartum survey (HPS 2001)

*The percent given for each infrastructure problem is for that problem only

salud pública de méxico / vol.46, no.1, enero-febrero de 2004 
The complete sample was characterized by infants whose mothers were between 20-34 years of age, lived in a formal union and exhibited low parity. Slightly less than one half of the sample reported living in a metropolitan area with at least 100000 inhabitants. The participants were relatively disadvantaged in terms of socioeconomic status. Four percent of the sample reported having received no education at all and over one quarter of the respondents did not complete a primary school education. With regard to household infrastructure, around $17 \%$ of the sample reported lack of indoor plumbing in the house where they spent the majority of their pregnancy and around 13\% reported not having an indoor water supply. Ten percent indicated living in a house with dirt floors while only around 3\% reported that their house did not have electricity.

With respect to behavioral practices, $8 \%$ reported smoking during pregnancy. This percentage is considerably lower than that found among women in the U.S. (23 percent) but higher than the percentage found among Mexican-born women in the U.S. (2.4 percent), suggesting a possible selection effect. ${ }^{17,25}$ Around $17 \%$ of the sample reported low weight gain ( $<7$ kilograms) indicating an inadequate maternal diet during pregnancy. In terms of prenatal care, the majority of the respondents reported having received some type of prenatal care prior to the birth of the infant. Almost two-thirds of the sample reported that they attended their first prenatal care visit sometime in the first three months of the pregnancy, whereas $24.5 \%$ attended their first visit sometime after the first trimester of the pregnancy. These distributions are slightly lower than those found among women giving birth in Instituto Mexicano del Seguro Social - (IMSS), Mexican Institute of Social Security (MISS) hospitals where around three fourths of all women reported receiving prenatal care within the first trimester. ${ }^{26}$ Around $12 \%$ of the sample reported that they never attended a prenatal care visit, which is nearly double the national estimate of $6.8 \% .{ }^{27}$

With regard to health problems, the majority of the sample $(80 \%)$ reported having experienced at least one health problem during the pregnancy. The high number of health problems is likely due to the wide range of problems included in this measure. Additionally, each problem was based on self-report, which may have artificially inflated each problem's incidence. Despite the high proportion of women that reported a health problem, only $5.8 \%$ were actually hospitalized at some point during the pregnancy.

Table II shows the results from logistic regression models of low birth weight. The results are presented as odds ratios. The first model presents the relation- ship between low birth weight and the sociodemographic and socioeconomic background factors. Most notably, only one of the predictor variables reaches statistical significance in the model predicting low birth weight. Women who gave birth to their first infant presented significantly increased odds of having a low birth weight infant. Although they operate in the expected direction, the rest of the sociodemographic and socioeconomic effects were not statistically significant in predicting the likelihood of giving birth to a low weight infant. In sharp contrast, the behavioral factors that were added in Model 2 appeared to be highly significant in predicting the odds of a low birth weight infant. Women who received some kind of prenatal care were less likely to give birth to a low weight infant, although the effect was more pronounced among those women who received prenatal care later on in the pregnancy. One of the reasons that early receipt of prenatal care was not as strongly associated with positive birth outcomes as was later receipt of prenatal care may be that some of the respondents that received their prenatal care in the first trimester of pregnancy may have initiated early care because their pregnancy was high-risk. Weight gain and smoking were two other maternal behavioral practices that were significantly related to the odds of a low-weight birth. Women who gained less than 7 kilograms presented significantly increased odds of having a low-weight birth. Additionally, women who did not know how much weight they gained were also at an increased risk of having a low birth weight infant. This association may have resulted from the possibility that one of the ways that women learn how much weight they gain during their pregnancy is through prenatal care appointments. An inability to estimate how much weight was gained throughout the pregnancy may be an indicator of a lack of prenatal care and medical attention during the pregnancy. In accordance with past findings, women who smoked during pregnancy also experienced more than a two-fold risk of giving birth to a low birth weight infant.

In the third model, the maternal health variables (those that are most closely associated with birth weight) were added. Not surprisingly, they were also the most strongly associated with the odds of giving birth to a low weight infant. Women who reported experiencing a health problem during the pregnancy had over a two-fold increased risk of having a low-weight birth and respondents who were hospitalized during the pregnancy had over four times the odds of giving birth to a low birth weight infant.

The next set of models tested the possibility that there were significant differences in the odds of receiv- 
Table II

Factors related to low birth Weight amorg a sample of Mexican Women, Hospital based post partum SURVey. Mexico, 2001

\begin{tabular}{|c|c|c|c|c|c|c|}
\hline & & & & & & \\
\hline & $\overline{\mathrm{OR}}$ & $95 \% \mathrm{Cl}$ & $\overline{\mathrm{OR}}$ & $95 \% \mathrm{Cl}$ & $\overline{\mathrm{OR}}$ & $95 \% \mathrm{Cl}$ \\
\hline Maternal age [20-34] & & & & & & \\
\hline$<20$ years & 1.24 & $0.77,2.00$ & 1.03 & $0.62,1.71$ & 1.02 & $0.60,1.73$ \\
\hline $35+$ years & 1.79 & $0.84,3.82$ & $2.04 \dagger$ & $0.90,4.62$ & $2.30 *$ & $1.07,4.97$ \\
\hline Union status [Formal union] & & & & & & \\
\hline Informal union & 1.00 & $0.62,1.63$ & 1.02 & $0.62,1.68$ & 1.00 & $0.58,1.72$ \\
\hline No union & 1.35 & $0.77,2.38$ & 1.35 & $0.74,2.47$ & 1.40 & $0.72,2.69$ \\
\hline Parity [Low parity] & & & & & & \\
\hline First birth & $1.67^{\ddagger}$ & $1.06,2.65$ & $1.95^{\S}$ & $1.19,3.18$ & $2.24^{\S}$ & $1.32,3.82$ \\
\hline High parity & 0.78 & $0.48,1.28$ & 0.72 & $0.42,1.22$ & 0.80 & $0.46,1.39$ \\
\hline Locality size $[<100,000]$ & & & & & & \\
\hline $100000+$ & 0.95 & $0.67,1.35$ & 0.90 & $0.62,1.31$ & 0.93 & $0.62,1.38$ \\
\hline Work during pregnancy [N 0 ] & & & & & & \\
\hline Yes & 0.76 & $0.44,1.30$ & 0.69 & $0.39,1.22$ & 0.63 & $0.35,1.14$ \\
\hline Maternal education [ $6+$ years] & & & & & & \\
\hline None & 1.26 & $0.53,2.99$ & 0.96 & $0.40,2.33$ & 0.98 & $0.40,2.40$ \\
\hline$<6$ years & 1.16 & $0.74,1.81$ & 0.96 & $0.59,1.58$ & 1.05 & $0.64,1.73$ \\
\hline N umber of infrastructure problems & 1.13 & $0.89,1.44$ & 1.20 & $0.94,1.53$ & $1.25 *$ & $0.97,1.60$ \\
\hline Prenatal care [ $\mathrm{N}$ o] & & & & & & \\
\hline Began in 1st trimester & & & 0.87 & $0.48,1.59$ & 0.83 & $0.42,1.63$ \\
\hline Began after 1st trimester & & & $0.54 \dagger$ & $0.27,1.07$ & $0.46^{\ddagger}$ & $0.21,0.99$ \\
\hline W eight gain [N ot low] & & & & & & \\
\hline Low weight gain & & & $2.25^{\S}$ & $1.36,3.71$ & $2.39 \S$ & $1.40,4.09$ \\
\hline Missing & & & $2.04^{\S}$ & $1.21,3.43$ & $2.08^{\ddagger}$ & $1.23,3.52$ \\
\hline Smoking [ $\mathrm{N}$ o] & & & & & & \\
\hline Yes & & & $2.12^{\ddagger}$ & $1.12,4.00$ & $1.88 *$ & $0.93,3.82$ \\
\hline Problems in pregnancy [ $\mathrm{N} 0$ ] & & & & & & \\
\hline Yes & & & & & $2.13^{\S}$ & $1.23,3.70$ \\
\hline Hospitalization in pregnancy [ $\mathrm{N}$ o] & & & & & & \\
\hline Yes & & & & & $4.20^{\#}$ & $2.11,8.38$ \\
\hline Intercept & -2.92 & & -3.02 & & -3.86 & \\
\hline Unweighted N & 563 & & 558 & & 556 & \\
\hline $\begin{array}{l}* p<0.1 \\
\neq p<0.05 \\
\S p<0.01 \\
\# p<0.001\end{array}$ & & & & & & \\
\hline Source: Hospital-based postpartum & & & & & & \\
\hline
\end{tabular}


ing prenatal care among the patient populations of the hospitals included in the sample. The first model in Table III examined the role of sociodemographic and socioeconomic variables in determining the receipt of prenatal care. In contrast to the model predicting low birth weight, the results demonstrated that the sociodemographic and socioeconomic factors were strongly related to the likelihood of receiving prenatal care. Women who were younger, single, and living in urban areas all presented significantly decreased odds of receiving prenatal care. In contrast, older women (35+), first births and women who worked during their pregnancies presented significantly increased odds of receiving care.

In the second model a measure of maternal health was added. Women who reported experiencing a problem during pregnancy presented five-fold increased odds of receiving prenatal care. This effect captured the fact that many women who were considered high-risk and / or were experiencing medical problems sought out prenatal care. Indeed, part of the high risk of prenatal care for older women was explained by experiencing more medical problems. The other effects were largely left unchanged, suggesting that decreased utilization of prenatal care among sociodemographically disadvantaged groups occurs largely outside of the context of maternal health problems.

\section{Discussion}

The present analysis utilized data from a recent postpartum hospital survey to investigate the factors associated with low birth weight, which is strongly associated with neonatal mortality and has been linked to a range of health problems later in life.

The multivariate analysis of low birth weight demonstrated the importance of behavioral factors in determining the odds of giving birth to a low weight infant. In contrast to the socioeconomic and sociodemographic factors, which were not significantly predictive of low birth weight, the receipt of prenatal care, smoking during pregnancy and weight gain were all significantly associated with the odds of low birth weight in our sample. One explanation for the absence of a significant effect of the socioeconomic and sociodemographic variables on the risk of low birth weight may involve the nature of the sample. The HPS was administered to a relatively socioeconomically disadvantaged segment of the population, reflected in the fact that all the women in the sample received their medical care from SSA hospitals and a large number reported receiving either no formal education or less than a primary school education. As such, the strength
Table III

Factors Related to prenatal CARE Utilization AMORG A SAMPLE OF MEXICAN WOMEN. Hospital based POSTPARTUM SURVEY, 2001

$\frac{\text { Model } 1}{\text { OR } 95 \% \mathrm{Cl}} \frac{\text { Model } 2}{\text { OR } 95 \% \mathrm{Cl}}$

Maternal age [20-34]

\begin{tabular}{lllll}
$<20$ years & $0.39^{\ddagger}$ & $0.16,0.99$ & $0.38^{\ddagger}$ & $0.15,0.95$ \\
\hline $35+$ years & $9.50^{\#}$ & $3.38,26.6$ & $9.15^{\#}$ & $2.88,29.04$
\end{tabular}

Union status [Formal union]

\begin{tabular}{lllll} 
Informal union & 0.87 & $0.29,2.63$ & 0.79 & $0.25,2.49^{\prime}$ \\
\hline & 0.28 & $0.10,0.82$ & 0.30 & $0.09,0.98$
\end{tabular}

$\begin{array}{lllll}\text { No union } & 0.28^{\ddagger} & 0.10,0.82 & 0.30^{\ddagger} & 0.09,0.98\end{array}$

Parity [Low parity]

\begin{tabular}{lllll} 
First birth & $3.01^{\ddagger}$ & $1.02,8.83$ & 2.32 & $0.73,7.30$ \\
\hline
\end{tabular}

$\begin{array}{lllll}\text { High parity } & 0.63 & 0.28,1.45 & 0.54 & 0.25,1.16\end{array}$

Locality size $[<100000]$ $100000+$

$\begin{array}{llll}0.34^{\S} & 0.15,0.76 & 0.31^{\S} & 0.13,0.73\end{array}$

Work during pregnancy [N 0$]$

Yes

$2.51^{\ddagger} \quad 1.07,5.93 \quad 2.42^{*} \quad 0.95,6.17$

Maternal education [6+ years]

\begin{tabular}{lllll}
$N$ one & 0.40 & $0.12,1.28$ & 0.37 & $0.10,1.39$ \\
\hline$<6$ years & 0.51 & $0.19,1.37$ & 0.48 & $0.16,1.43$
\end{tabular}

N umber of infrastructure problems $\quad 0.77 \quad 0.45,1.31 \quad 0.80 \quad 0.50,1.27$ Problems in pregnancy [ $\mathrm{N}$ o]

Yes

$5.20^{\#} 2.40,11.30$

\begin{tabular}{lcc} 
Intercept & 3.10 & 2.15 \\
\hline Unweighted N & 563 & 561 \\
$* p<0.1$ & \\
$\neq p<0.05$ & \\
$\$ p<0.01$ & \\
$\# p<0.001$ & &
\end{tabular}

Source: Hospital-Based postpartum survey (HPS 2001)

of individual-level socioeconomic effects on the odds of low birth weight may be more pronounced with a nationally representative survey sample. An additional explanation involves the relatively small sample size of the HPS. However, the oversampling of low birth weights gave increased stability to the estimates predicting the odds of low birth weight.

The strong effect of behavioral factors on birth weight is what we might expect given that low birth weight is more affected by processes associated with birth. ${ }^{28}$ In contrast to many of the conditions tied to postneonatal mortality, low birth weight tends to operate more 
directly through maternal influences and pregnancyrelated pathways. In accordance with past studies, this analysis showed that these factors included receipt of prenatal care, inadequate and unknown weight gain, smoking, and pregnancy complications. ${ }^{18}$ It is expected that these factors would be more predictive of low birth weight given that they are most causally proximate to maternal health. Indeed, it appears that many of the behavioral factors operated through maternal health variables to influence low birth weight, as two of the behavioral effects decreased and became insignificant when the maternal health variables were added to the model.

The importance of individual behaviors for contributing to the risk of low birth weight highlights the need to focus on the prevention of risky behaviors and encourage healthy lifestyles during pregnancy. To this end, the analysis also estimated the odds of obtaining prenatal care during pregnancy. Prenatal care is understood to improve birth outcomes by encouraging healthy behaviors and also by identifying and treating maternal morbidities. ${ }^{29}$ The findings indicated that sociodemographic and socioeconomic indicators are important for determining the receipt of prenatal care. The results demonstrated that several of the sub-groups of women most in need of prenatal care did obtain it. "Higher risk" pregnancies, including those involving women over the age of 35 , first births and women with health problems, were strongly predictive of receiving prenatal care. Additionally, women who were employed during pregnancy were significantly more likely to have received prenatal care. It is unlikely that this effect was due to increased insurance coverage, given that all the women in the sample attended SSA hospitals. Instead, employment may have resulted in increased prenatal care usage to the extent that it provides women with more income and information from their co-worker social network.

On the other hand, several other sub-groups appear to be considerably less likely to receive prenatal care. The results demonstrated that teenagers and single women presented significantly decreased odds of receiving prenatal care. These findings confirm what has been shown for other populations, namely that disadvantaged sociodemographic status is linked to decreased utilization of prenatal care..$^{22}$ Additionally, the findings demonstrated that women living in urban areas (100 000+ inhabitants) also presented significantly decreased odds of receiving prenatal care. While this effect may be unique to this sample, it is important to the extent that it suggests that women living in urban areas in Western Mexico are at an increased risk of not receiving prenatal care during pregnancy.
Whether this effect was due to an issue of access or utilization, it deserves further exploration.

Taken together the evidence presented here suggests that a) the incidence of low birth weight in this sample of women from Western Mexico is strongly associated with maternal lifestyle behaviors and $b$ ) prenatal care utilization, which has been shown to most directly affect women's lifestyle choices, is highly variable by sociodemographic status. Most notably, socially disadvantaged women as measured by age, residence and marital status, are less likely to receive prenatal care. This gap in prenatal care utilization is particularly salient in light of the understanding that disadvantaged social position affects ability to control everyday life circumstances and may influence preferences toward insalubrious salutary lifestyle behaviors. ${ }^{30}$ As a result, many of the women that are not receiving prenatal care may actually include those that need it most. These findings highlight the need to increase efforts to encourage prenatal care utilization among higher risk segments of the population.

Finally, in addition to efforts aimed at modifying maternal behavioral patterns, one must not disregard the important, albeit indirect, role of socioeconomic background factors in contributing to the incidence of low birth weight. All too often the key role of maternal lifestyle behaviors in contributing to infant health outcomes works to deflect attention away from the more difficult problem of social environment. This possibility is particularly relevant in the study of low birth weight, given its close proximity to maternal and pregnancy-related pathways. Maternal lifestyle behaviors are best viewed, not only as individual characteristics, "but as the patterned response of social groups to the realities and constraints of the external environment." ${ }^{31}$ Future public health approaches to lowering the rate of low weight infants in Mexico must address both sets of factors, improving maternal lifestyle choices by increasing access utilization and quality of care, while at the same time remaining committed to addressing many of the more intractable socioeconomic disparities that continue to indirectly contribute to the incidence of low birth weight.

\section{References}

1. PartidaV. Situación demográfica actual. En: Consejo N acional de Población, ed. Situación D emográfica de México, 2002. México, D F: 2003.

2. Consejo N acional de Población. La situación demográfica de México. México, DF: Conapo, 1998.

3. Frenk J, Bo badilla JL, Sepúlveda J, C er vantes ML. Health transition in middle-income countries: $\mathrm{N}$ ew challenges for health care. Health Policy Plann 1989; 4:29-39. 
4. PartidaV, G arcía JE. El cambio epidemiológico reciente. En: ed. Situación demográfica de México, 2002. México, DF:C onsejo N acional de Población, 2003:17-27.

5.W ilcox AJ. $0 \mathrm{n}$ the importance-and the unimportance of birthweight. Int Epidemiol Assoc 2001; 30:1233-1241.

6. Boardman JD, Powers DA, PadillaYC, Hummer RA. Low birth weight, social factors, and developmental outcomes among children in the United States. Demography 2002; 39(2):353-68.

7. C oria-Soto IL, Bobadilla JL, N otzon F.The effectiveness of antenatal care in preventing intrauterine growth retardation and low birth weight due to preterm delivery. Int J Q ual Health Care 1996; 8:13-20. 8.A lexander GR, Kogan MD, Himes JH. 1994-1996 U.S. singleton birth weight percentiles for gestational age by race, hispanic origin, and gender. Matern Child Health J 1999; 3:225-231.

9.A lexander GR, Milton K.Assessing the role and effectiveness of prenatal care: History, challenges, and directions for future research. Public Health Rep 2001; 116:306-316.

10. Cramer JC. Social factors and infant mortality: Identifying high-risk groups and proximate causes. Demography 1987; 24:299-322.

11. Cramer JC . Racial and ethnic differences in birthweight:The role of income and financial assistance. Demography 1995; 32(2):231-247. 12.Avila-Rosas H, C asanueva E, Barrera A, Cruz I, Rojo MC.Algunos determinantes biológicos y sociales del peso al nacer. Salud Publica Mex 1988; 30(1):47-53.

13.Zúñiga EH, López AR. Vínculos entre la desnutrición infantil y la condición social de la madre, la familia y la pobreza. En: Bringas $\mathrm{HHH}$, Menkes C, eds. La población de México al final del siglo XX.Vol. 1 México DF: Universidad N acional Autónoma de México, 1998:299-314. 14. Cerón-Mireles P, Sánchez-C arrillo Cl, Harlow S, N úñez-U rquiza RM. Condiciones de trabajo materno y bajo peso al nacer en la Ciudad de México. Salud Publica Mex 1997; 39:2-10.

15. Hernández-Peäna P, Kageyama ML, C oria I, Hernández B, Harlow S. Condiciones de trabajo, fatiga laboral y bajo peso al nacer en vendedoras ambulantes. Salud Publica Mex 1999; 41(2):101-109. 16. Cogswell ME,Yip R. The influence of fetal and maternal factors on the distribution of birthweight. Semin Perinatol 1995; 19:222-240. 17. Finch BK, Frank R, Hummer RA. Racial/ethnic disparities in infant mortality:The role of behavioral factors. Soc Biol 2000; 47(3-4):244-263.
18. Chomitz VR, Cheung W Y, Lieberman E.The role of lifestyle in preventing low birth weight. Future Child 1995; 5:121-138.

19. Kleinman JC, Kessel SS. Racial differences in low birth weight. Trends and risk factors.N Engl J Med. 1987; 317(12):749-753.

20. Infante C, Schlaepfer L. Las variables socioeconómicas en la investigación en salud pública en México. Salud Publica Mex. 1994; 36(4):365-373

21. Institute of M. N utrition during pregnancy. W ashington, DC: N ational Academy Press, 1990.

22. Alexander $\mathrm{GR}$, Korenbrot $\mathrm{CC}$. The role of prenatal care in preventing low birth weight. Future Child 1995; 5:103-120.

23. Menec VH, Chipperfield JG, Perry RP. Self-perceptions of health:A prospective analysis of mortality, control, and health. Gerontol B Psychol Sci Soc Sci 1999; 54(2):85-93.

24. Statacorp. Stata statistical software. College Station: Stata Corporation, 2001.

25. Hummer RA, Biegler M, DeTurk PB,Forbes-Frisbie W P, Hong Y et al. Race/ethnicity, nativity, and infant mortality in the U nited States. Soc Forces 1999; 77:1083-1118.

26. Martínez-G onzález L, Reyes-Frausto S, García-Peña MDC. Utilización adecuada de la atención prenatal en el Instituto Mexicano del Seguro Social. Salud Publica Mex 1996; 38:341-351.

27. Consejo $\mathrm{N}$ acional de Población. La situación demográfica de México, 1998. En: Consejo N acional de Población, ed. México, DF: Con, 1999: 27-35.

28. Gortmaker SL,W ise PH.The first injustice: Socioeconomic disparities, health services technology, and infant mortality. Annual Rev Sociol 1997; 23.

29. Hughes D, Simpson L.The role of social change in preventing low birth weight. Future child 1995; 5(1):87-102.

30. Jones $C$. Levels of racism: $A$ theoretic framework and a gardener's tale. Am J Public Health 2000; 90:1212-1215.

31. Zambrana RE, D unkel-Schetter C, Collins N L, Scrimshaw SC. Mediators of ethnic-associated differences in infant birth weight.J of Urban Health 1999; 76:102-116. 